\title{
ONDAS ULTRASSÔNICAS: BIOEFEITOS SOBRE CÉLULAS DE LEVEDURAS
}

\section{ULTRASONIC WAVES: BIOEFFECTS ON YEAST CELLS}

\section{Roberto Naves Domingos ${ }^{1,2}$, Dejanira de Franceschi de Angelis $^{3}$, Carlos Renato Corso ${ }^{3}$, Amauri Antonio Menegário ${ }^{1}$, Rosilene Naves Domingos ${ }^{4}$}

\author{
${ }^{1}$ UNESP - Univ.Estadual Paulista, Campus de Rio Claro, Centro de Estudos \\ Ambientais, CEA, Av 24 A 1515 CEP: 13.506-900, Bela Vista, Rio Claro, São \\ Paulo - Brasil
}

${ }^{2}$ UNESP - Univ.Estadual Paulista, Campus de Rio Claro, Instituto de Geociências e Ciências Exatas, IGCE, Departamento de Fisica, Av 24 A 1515 CEP: 13.506-900, Bela Vista, Rio Claro, São Paulo - Brasil

${ }^{3}$ UNESP - Univ.Estadual Paulista, Campus de Rio Claro, Instituto de Biociências, IB, Departamento de Bioquimica e Microbiologia, Av 24 A 1515 cep 13506900, Bela Vista, Rio Claro, São Paulo - Brasil

${ }^{4}$ UNITINS - Fundação Universidade do Tocantins, 108 Sul, Alameda 11, Lote 3, Centro, CEP: 77.020-112 Caixa Postal 173, Palmas Tocantins - Brasil

RESUMO

Aplicações de ultrassom foram utilizadas a partir de 1912, com o objetivo principal de detectar icebergs para evitar acidentes marítimos. Observou-se, também, que algas e peixes apareciam destruídos e mortos no entorno dos navios e submarinos equipados com sonar. As pesquisas e estudos sobre ultrassom muito evoluíram após a descoberta de transdutores piezoelétricos, possibilitando sua aplicação nas diferentes áreas da ciência e da tecnologia. Como exemplo, é citada como importante ferramenta em microcirurgias, detecção de fadiga mecânica na indústria espacial, catálise sonoquímica, biotecnologia e outros. $\mathrm{O}$ trabalho aqui apresentado mostra uma aplicação de ultrassons na forma pulsada em biotecnologia, com a finalidade de melhorar a fermentação de cultura etanólica em suspensão de leveduras e caldo de cana-de-açúcar. Nas experiências foram utilizados como gerador de ultrassom um oscilador Sonics VCX-600 $(20 \mathrm{KHz})$, acoplado com transdutor de cavidade ressonante e guia de onda do tipo sonda. Os experimentos foram realizados em reatores de vidro temperado de capacidade de $200 \mathrm{~mL}$ que continham caldo de cana e Saccharomyces cerevisiae em suspensão. Os parâmetros analisados foram teor alcoólico (cromatografia em fase gasosa FID), viabilidade celular (Câmara de Neubauer), ATR (método refratométrico). Análise dos resultados demonstraram que a taxa de etanol produzido chegou a $12 \%$ a mais do que os teores obtidos nos reatores não irradiados, sugerindo que existem vantagens na ativação ultrassônica. Os resultados indicaram que o ultrassom é uma promissora alternativa para ser utilizada na produção de etanol, biocombustíveis e outros subprodutos da indústria sucroalcooleira e álcool química.

Palavras-chave: Ultrassom. Saccharomyces cerevisiae. Catalise Sonoquimica. Fermentação Etanólica. 


\begin{abstract}
Applications of ultrasound were starting from 1912, with the primary objective the detection of icebergs on prevention of maritime accidents. Algae, fish deaths and destruction were observed in the vicinity of sonar that equipped ships and submarines during the First World War. The evolutions of research and studies with ultrasound have big advances following the discovery of piezoelectric transducers in science and technology. As an example, it can mention its application in microsurgery, fatigue detection in aerospace mechanics, sonochemical catalysis, biotechnology and others. This paper presented here aims to demonstrate the application of ultrasonic in pulsed mode beams in biotechnology with the aim of improving the fermentation of a culture broth containing biological agents. In these experiments we used as ultrasound equipment and oscillator Sonics VCX-600 $(20 \mathrm{KHz})$, probe type wave guide. The experiments were conducted in a glass reactor of $200 \mathrm{~mL}$ of biomaterial containing cane juice and Saccharomyces cerevisiae in suspension. The parameters analyzed were related to the content Alcohlic (FID gas chromatography), and cell viability (Neubauer chamber), TRS (refractometry). Analysis of results showed that the total production exceeded in irradiated samples compared to normal fermentation (without ultrasound), suggesting additional advantage of ultrasound activation. Lastin Trials $1400 \mathrm{~min}$, showed ethanol production systems $12 \%$ more than non-enabled systems. In this context alternatives for ethanol production, bio fuel and many other byproducts of the alcohol industries and chemicals could benefit from the use of ultrasound beams in this range of frequencies.
\end{abstract}

Keywords: Ultrasound. Saccharomyces cerevisiae. Sonochemical Catalysis. Fermentation Ethanol.

\title{
1. INTRODUÇÃO
}

Ondas ultrassônicas ao interagir com o meio podem ser absorvidas, atenuadas ou refletidas, produzindo efeitos térmicos e não térmicos. Os primeiros acompanham a aplicação do ultrassom em modo contínuo, enquanto que estes últimos são fenômenos característicos do uso do ultrassom no modo pulsado. Ambos os efeitos são acompanhados de fenômenos químicos como formação de radicais livres e hidrolização, fenômenos físicos como a cavitação e microcorrenteza acústica, e efeitos biológicos como desnaturação de enzimas, modificação na estrutura de DNA e muitos efeitos durante a interação com microrganismos como fungos e leveduras.

O ultrassom pulsado não produz efeitos térmicos e no lugar da cavitação predomina a microcorrenteza acústica onde o fluido de uma suspensão biológica, por exemplo, realiza um movimento conectivo. Ao atingir as células da suspensão a microcorrenteza interage mecanicamente com a membrana celular, sem destruí-la, induzindo uma diminuição da permeabilidade, facilitando assim as trocas intra e extracelular. Esse efeito é conhecido como micromassagem.

Este trabalho aqui apresentado tem como objetivo mostrar a aplicação de ultrassons na forma pulsada em biotecnologia, com a finalidade de melhorar a fermentação de cultura etanólica em suspensão de leveduras e caldo de cana-de-açúcar.

\section{MATERIAL E MÉTODOS}

O experimento foi desenvolvido em um gerador ultrassônico: Processador VC-600 da Sonics Inc $20 \mathrm{KH}_{2}$, tipo sonda, refratômetro, banho termostatizado, microscópio, reatores de vidro $200 \mathrm{~mL}$. Como meio de cultura utilizou-se mosto esterilizado a $5^{\circ}$ BRIX. Para cada litro deste meio adicionou-se 250 gramas de fermento comercial e biocidas. Esta suspensão celular foi mantida a temperatura ambiente por $12 \mathrm{~h}$ e em seguida dividida em dois volumes iguais. 
Um dos volumes permaneceu como controle do experimento e o outro foi submetido à irradiação ultrassônica $\left(50 \mathrm{w} / \mathrm{cm}^{2}, 20 \mathrm{khz}\right)$ em intervalos de $45 \mathrm{~min}$. A cada intervalo de noventa minutos, amostras ativadas e não ativadas foram avaliadas simultaneamente, para as quais se determinou os teores de açúcar e etanol. O açúcar redutor total foi determinado pelo método sugerido por Horii (1991). Os cálculos de rendimento seguiram a metodologia de Stupiello (1981).

\section{RESULTADOS E DISCUSSÕES}

Pelos dados apresentados temos que inicialmente não há uma mudança significativa na produção de etanol nas células ativadas, com BRIX até 8,0, porém quando o mesmo atingiu próximo a 7,0 começou a aumentar a produção de etanol tendo um acréscimo de 4,31 com BRIX 7,0, 11,12\% álcool com BRIX 5,0, 12,5\% com BRIX 4,8 decaindo para 5,4\% com BRIX de 4,0, o tempo de melhor rendimento foi algo em torno de 270 a 360 minutos de processos fermentativo (Tabela 1). Os experimentos ainda estão em nível de bancada podendo em um futuro próximo vir a ser testado em escala piloto ou mesmo industrial.

Tabela 1 - Desempenho de Saccharomyces cerevisiae em sistema fermentativo sob ativação VS pulsado comparado com um sistema controle sem US, por um período de até 1.440 minutos.

\begin{tabular}{|l|c|c|c|c|c|c|c|}
\hline $\begin{array}{c}\text { ATIVAÇÃO } \\
\text { TEMPO } \\
(\text { MIN) }\end{array}$ & \multicolumn{3}{|c|}{ CONTROLE } & \multicolumn{4}{c|}{ CÉLULAS ATIVADAS } \\
\cline { 2 - 8 } & $\mathrm{C}_{\text {BRIX }}$ & $\begin{array}{c}\text { ART } \\
(\%)\end{array}$ & $\begin{array}{c}\text { T.A. } \\
\text { g GL } \\
(\%)\end{array}$ & CRRIX $_{\text {BRT }}$ & $\begin{array}{c}\text { ART } \\
(\%)\end{array}$ & $\begin{array}{c}\text { T.A. } \\
\text { g GL } \\
(\%)\end{array}$ & $\begin{array}{c}\text { ACRÉSCIMO } \\
\text { DERODUÇÃO } \\
\text { ETANOL }\end{array}$ \\
\hline 0 & 10,0 & 5,30 & 0,40 & 10,0 & 5,45 & 0,4 & 0 \\
\hline 90 & 8,0 & 5,0 & 1,22 & 8,80 & 4,89 & 0,96 & $-21,31$ \\
\hline 180 & 7,0 & 3,55 & 1,84 & 7,0 & 2,96 & 1,92 & 4,34 \\
\hline 360 & 5,0 & 0,88 & 2,95 & 5,0 & 0,88 & 3,28 & 11,12 \\
\hline 1440 & 4,8 & 0,68 & 3,20 & 4,8 & 0,77 & 3,60 & 12,50 \\
\hline
\end{tabular}

\section{CONCLUSÕES}

Nas condições de cultivo aqui utilizadas, além dos microrganismos estudado, conclui-se que:

a) A ativação ultrassônica altera a absorção de açúcar redutor total (ATR);

b) A ativação ultrassônica reduz o tempo da produção de etanol;

c) Número de células mortas abaixo de $20 \%$ se deve ao fato da cavitação não ser predominante na ativação pulsada;

d) Com o avanço tecnológico, reatores ultrassônicos com capacidade de $20 \mathrm{~m}^{3} / \mathrm{h}$ estão disponíveis comercialmente proporcionando o uso desta metodologia em escala comercial. 


\section{REFERÊNCIAS}

BUCALON, J.A.; PALMA, M.S. Sonochemical effects in Saccharomyces cerevisiae extract: oxidation of hydroxil and thiol groups. Ultrasonics International Conf. Proc., p. 745-750, 1987.

BUCALON, J.A.; PALMA, M.S. DNA disrupture induced by ultrasound as usefull tool in molecular biology. Ultrasonics International Conf. Proc., p. 91-94, 1991.

CHURCH, B.D. and HALVORSON, H. Dependence of the heat resistance of bacterial endospores on their dipicolinic acid content. Nature, vol. 183, p. 123-125. 1986.

CLARKE, P.R. and HILL, C.R. Biological action of ultrasound in relation to the cell cycle. Experimental Cell Research. p. 443-444, 1969 b.

HORII, J.; GONÇALVES, R.H. Um método alternativo para determinação de AR e ART. STAB Açúcar, Álcool e Subprodutos, Piracicaba, v. 10, n. 2, p. 45-47, nov./dez., 1991.

STUPIELLO, J.P.; HORII, J. Condução da Fermentação alcoólica. Saccharum, v.4, n. 17, p. 43-46, 1981.

WILLIAMS, A.R. Ultrasound: Biological Effects and Potential Hazards. $1^{\text {a }}$ (ed.) Orlando: Academic Press, p. 157-253, 1983.

WILLIAMS, A.R.; NYBORG, W.L. Hemolysis near and ultrasonically pulsating gas bubble. Science, vol. 169, p. 869-873, 1970. 